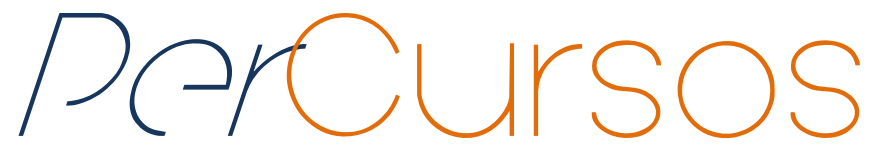

\title{
O educador infantil: políticas e formação na contemporaneidade
}

\begin{abstract}
Resumo
A Educação Infantil figura como um direito social, considerando as repercussões da Lei de Diretrizes e Bases da Educação Nacional vigente desde 1996. Este artigo, de natureza teórica, pretende trazer elementos para entender as formulações normativas no quadro da atual Lei de Diretrizes e Bases da Educação Nacional (Lei n. 9.394, de 20 de dezembro de 1996), tendo em vista as metas do Plano Nacional de Educação (PNE) de 2001, com a formação e a atuação de professoras e professores. Os aspectos teóricos e metodológicos da pesquisa focalizam a importância da formação do professor e a do fortalecimento de práticas pedagógicas mediadoras da aprendizagem e desenvolvimento das crianças em creches e préescolas no que diz respeito às especificidades para atuação na Educação Infantil.
\end{abstract}

Palavras-chave: Curso de Pedagogia. Infância. Políticas educacionais.

\author{
Luiza Franco Duarte \\ Mestranda em Educação pela \\ Universidade Estadual do Oeste \\ do Paraná - UNIOESTE. \\ Ifrancoduarte@gmail.com
}

\section{Maria Cecília Braz Ribeiro de Souza \\ Doutorado em Educação. \\ Professora da Universidade \\ Estadual do Oeste do Paraná - UNIOESTE. \\ ceciliabrazrib@yahoo.com.br}

\footnotetext{
Para citar este artigo:

DUARTE, Luiza Franco; SOUZA, Maria Cecília Braz Ribeiro de. O educador infantil: políticas e formação na contemporaneidade. Revista PerCursos. Florianópolis, v. 14, n.26, jan./jun. 2013. p. $26-39$.
}

\section{DOI: $10.5965 / 198472421426201326$}

http://dx.doi.org/10.5965/198472461426201326 


\title{
The childhood educator: policies and training in contemporary
}

\begin{abstract}
The childhood education is considered a social right, considering the repercussion of the Lei de Diretrizes e Bases da Educação Nacional, valid since 1996. The objective of this theorical article is intended to bring understanding elements of the normative formulations within the scenario of the current National Education Bases and Guidelines Law (law n. 9.394, as of December 20, 1996), bearing in mind the goals of the 2001 National Plan for Education (PNE) thus contribute to the formation and practice of female and male teachers. The theoretical and methodological aspects of research focusing the importance of the training teacher and educational practices mediating learning and development of young children in day care centers and pre-schools, with regard to the specific characteristics for future performance in kindergarten.
\end{abstract}

Keywords: Course of Pedagogic. Childhood.

Educational Policies. 


\section{Introdução}

A Educação Infantil no contexto brasileiro está assegurada legalmente enquanto direito público e subjetivo à educação de crianças de zero a cinco anos de idade a partir da promulgação da Constituição Federal de 1988. Apesar de passados 25 anos desse processo sociopolítico, na contemporaneidade - século XXI - ainda podem ser observados embates políticos e pedagógicos a propósito da formação docente do profissional atuante nessa primeira etapa da Educação Básica.

Sobre esta fundamentação, o presente artigo procura problematizar a formação de professores que atuam na Educação Infantil, no sentido de apontar as especificidades profissionais necessárias ao desempenho de um trabalho pedagógico pautado nos preceitos de cuidar, educar e proteger a infância de crianças entre zero e cinco anos de idade.

O percurso enveredado na compreensão de um desenho político na formação política e pedagógica de professores para a Educação Infantil utiliza-se de fontes primárias, tais como a Constituição Federal de 1988, a Lei de Diretrizes e Bases da Educação Nacional de 1996 e o Plano Nacional de Educação de 2001 a 2010; e fontes secundárias sobre a temática problematizada, que são Almeida (2007), Bonetti (2006), Campos (1999) Duarte; Souza (2011), Franco (2008), Franco; Libâneo; Pimenta (2007), Freire (1987), Kuenzer (2002), Mello (2004), Paula (2010), Prestes (2003). A opção metodológica pela pesquisa documental e bibliográfica articula a possibilidade de reunir e analisar as informações e os conhecimentos historicamente acumulados e disponíveis em dado contexto sócio-histórico.

Na pesquisa documental, compreende-se que os documentos oficiais e as próprias legislações "constituem geralmente a fonte mais fidedigna de dados. Podem dizer respeito a atos individuais, ou, ao contrário, a atos da vida política, de alcance municipal, estadual ou nacional” (MARCONI; LAKATOS, 2010, p. 166). Já a pesquisa bibliográfica se elabora enquanto processo textual que "[...] não é a mera repetição do que já foi dito ou escrito sobre certo assunto, mas propicia o exame de um novo tema sob novo enfoque ou abordagem, chegando a conclusões inovadoras" (MARCONI; LAKATOS, 2010, p. 166). 
De modo geral, esses recursos documentais e bibliográficos embasam os mais diversos tipos de estudos, fundamentando as interpretações relacionadas ao problema inicialmente apresentado.

Assim, apresenta-se um estudo documental e bibliográfico para subsidiar o entendimento das políticas públicas de formação de professores para a Educação Infantil.

A organização do trabalho pedagógico desenvolvido na primeira etapa da Educação Básica, a Educação Infantil, reitera e consolida a intencionalidade educativa do professor enquanto garantia do processo de transmissão e apropriação dos bens culturalmente construídos e assimilados pela humanidade às crianças de zero a cinco anos. Esta afirmação e informação constitui a base da presente análise. Ela confirma a valorização em geral dos profissionais da Educação, e principalmente a dos educadores da infância, pois é nesta fase que ocorre a materialização de uma formação teórica para a efetivação de uma práxis humanizadora.

Para tratar da problemática proposta, este texto é organizado em três momentos. Inicialmente, apresentam-se as principais legislações brasileiras que tratam especificamente da formação do professor atuante na Educação Infantil. No segundo momento, abordam-se as singularidades pedagógicas que essa primeira etapa da Educação Básica incorpora ao trabalho docente. Na terceira parte, busca-se compreender os desafios e as perspectivas da formação de professores para a Educação Infantil no curso de Pedagogia. Nas considerações finais, reitera-se que a formação docente para atuar na primeira etapa da Educação Básica deve incluir o conhecimento teórico e técnico sobre e para a Educação da primeira Infância.

\section{As legislações brasileiras sobre a formação de professores}

Compreende-se que a Constituição Federal do Brasil (CF), de 1988, e a Lei de Diretrizes e Bases da Educação Nacional (LDBEN) n. 9.394, de 1996, garantem a educação como direito de todos e dever da família e do Estado. 
Salienta-se que "o texto constitucional acolheu a demanda da Educação Infantil como direito da criança e dever do Estado. Já a LDBEN de 1996 (Lei Federal n. 9394/1996) inovou ao colocar a Educação Infantil como uma etapa da Educação Básica" (PAULA, 2010, p. 61). Na realidade, a Constituição Federal de 1988 não realizou milagres quanto ao atendimento da criança pequena, mas reafirmou na letra da lei um movimento da própria sociedade em aspectos de esclarecimentos sobre a importância formativa da Educação Infantil, tornando o atendimento complementar ao da família.

Sobre a formação de professores, na LDBEN de 1996, encontra-se explicitado:

A formação de docentes para atuar na educação básica far-se-á em nível superior, em curso de licenciatura, de graduação plena, em universidades e institutos superiores de educação, admitida, como formação mínima para o exercício do magistério na Educação Infantil e nas quatro primeiras séries do ensino fundamental, a oferecida em nível médio, na modalidade normal (BRASIL, 1996, art. 62).

Em outras palavras, entende-se que a LDBEN de 1996 estabelece legalmente que a formação do professor dos anos iniciais do Ensino Fundamental, e também da Educação Infantil, deve ocorrer em nível superior, estabelecendo que tal formação se dará em universidades e institutos superiores de educação, nas licenciaturas e em cursos normais superiores. Cabe enfatizar que cursos normais de nível médio seriam admitidos como a formação mínima exigida para o ingresso no trabalho docente, tanto no âmbito da Educação Infantil e quanto no do Ensino Fundamental até o ano de 2007, em decorrência do estabelecimento da Década da Educação (1997-2007).

Além disso, o processo de seleção e admissão de professores que atuam na rede pública e privada deve assegurar a formação específica na área mínima exigida pela lei que ordena a Educação brasileira. Especifica-se, aos professores que atuam na rede pública que a admissão se dará por concurso, ou seja, a LDBEN estabelece que, para o exercício da função docente, sejam realizados concursos para professores, os quais terão progressão funcional mediante qualificação.

Por isso, o Plano Nacional de Educação (PNE), Lei n. 10.172 de 2001, foi considerado, juntamente com a Constituição Brasileira e com a Lei de Diretrizes e Bases da Educação Nacional (LDBEN), uma das bases normativas que sustentam o pensar e 
refletir da educação no País. O PNE estabeleceu 298 metas para todos os níveis e modalidades de ensino, abordando, principalmente, a formação de professores, o financiamento e a gestão da educação no Brasil.

É clara a ênfase desse documento do PNE em abordar: os conhecimentos sobre infância e suas necessidades básicas; a potencialização do desenvolvimento cultural infantil, como forma de constituir uma demanda aos cursos de formação professores para a Educação Infantil que devem promover uma atenção especial à formação humana, à questão de valores e às habilidades específicas para tratar com seres tão abertos ao mundo e tão ávidos de explorar e conhecer, como são as crianças (PNE, 2001).

Com a promulgação destas legislações, extraem-se algumas inferências teóricas, sobretudo porque os professores que atuam na docência da Educação Infantil passam a ser reconhecidos como profissionais com direito a formação em serviço. Mas cabe observar que durante a década de 1990, erroneamente, se difundiu a ideia de que faltava qualidade no exercício da docência porque os professores não possuíam profissionalismo, fato que começou a ser debatido no âmbito governamental, de acordo com Bonetti (2006).

Portanto, a formação inicial e continuada dos professores de Educação Infantil constituem-se em direitos que devem ser assegurados a todos os profissionais da Educação pela União, estados e municípios, sobretudo mediante a inclusão e discussão de planos de carreira (cargos e salários) do magistério, para que de fato aconteça a valorização dos professores de Educação Infantil.

Para compreender a relevância de uma formação política do professor que atua na docência da Educação Infantil no Brasil, tratar-se-á, no próximo item, das singularidades pedagógicas que essa primeira etapa da Educação Básica incorpora ao trabalho docente.

\section{A mediação do professor na Educação Infantil: primeiras aproximações}

A história humana só pôde ser construída porque o homem não parou de transformar suas condições de vida e a si mesmo. "Ao mesmo tempo, todo o 
conhecimento e todos os objetos que foi criando não pararam de ser transmitidos de uma geração para outra [...]" (MELLO, 2004, p. 137), por meio do trabalho, atividade criadora e produtiva específica do homem.

O professor, segundo a perspectiva histórico-cultural, é entendido como mediador das relações de aprendizado, pois a ação docente “[...] propõe a atividade, amplia e qualifica a atividade iniciada pela criança, interfere sempre que necessário para garantir, com as atividades propostas que cada criança se aproprie das máximas qualidades humanas" (MELLO, 2006, p. 197).

Assim:

Quando lançamos nosso olhar sobre a história do atendimento à criança no Brasil, percebemos o quanto esse "serviço" sempre teve uma forte ligação com as questões de gênero (delegava-se à mulher, por causa de seu "instinto" materno), com as questões de condição social (eram organizadas instituições principalmente para as crianças pobres, indesejadas e abandonadas), e, um pouco mais tarde, com a questão econômica, quando a mulher, em função do empobrecimento da classe média e da mobilização dos movimentos feministas, entrou no mercado de trabalho (PRESTES, 2003, p. 3).

Historicamente, os anos 1980 foram extremamente importantes e produtivos em relação à Educação Infantil, pelos movimentos populares que se organizaram em prol dos direitos dos trabalhadores, principalmente das mulheres, e assim reivindicaram o atendimento às crianças pequenas.

$\mathrm{Na}$ contemporaneidade, as instituições que ofertam Educação Infantil são integrantes dos sistemas de ensino público ou privado, denominadas creches e préescolas. O atendimento a cada grupo de crianças divide-se pelo critério de faixa etária (de zero a três anos na creche, e de quatro a cinco anos na pré-escola).

Por isso, Almeida (2007) destaca a necessidade da formação inicial e continuada dos professores que atuam na Educação Infantil como recurso político e pedagógico que legitima, oferecendo suporte formativo às especificidades da infância, e possibilita uma sólida formação teórico-prática, permitindo aos professores desenvolverem uma ação 
docente situada, contextualizada e, acima de tudo, que respeite a criança como ser integral, em processo de desenvolvimento e de constituição do aspecto humano.

O professor é um intelectual em processo contínuo de formação. Pensar a formação significa pensá-la como "continuum", uma vez que os professores reelaboram os saberes iniciais em confronto com suas experiências práticas, cotidianamente vivenciadas nos contextos educativos, num processo de auto-formação (ALMEIDA, 2007, p. 1-2).

É importante que o processo de humanização tenha caráter pedagógico, e que a práxis adotada ofereça à criança diversidade e contextualização, de modo que ela possa atribuir sentidos às atividades realizadas.

Deste modo, o aprendizado, que tem início desde o nascimento da criança, permite a ela atribuir significados a partir das mediações das experiências sociais e das vivências. A mediação docente promove mudanças qualitativas no psiquismo de quem ensina e de quem aprende pela possibilidade dos indivíduos de estabelecer novas relações com o mundo objetivo. Assim, a organização do tempo e espaço na Educação Infantil não acontece na mesma rotina, nem na sequência da escola no Ensino Fundamental.

A organização do trabalho pedagógico na Educação Infantil compõe-se de atividades que envolvem adultos e crianças em momentos de múltiplas relações sociais: a mediação pedagógica tem a responsabilidade de intervir, quando se faz necessário, e de acompanhar as tomadas de decisões que propiciem condições adequadas de vida e educação.

A vivência da criança na Educação Infantil sinaliza a importância do processo pedagógico na formação humana, que é o que se propõem as políticas públicas no âmbito educacional, que fortalecem o direito e o acesso a múltiplas linguagens e as experiências diversificadas; concomitantemente, enaltecem a ação planejada para a apropriação de capacidades essencialmente humanas (DUARTE; SOUZA, 2011).

Por isso:

deve-se ter em mente que a simples formação oficial não pode e nem deve ser vista como a única exigência para se tornar professor de creche ou pré-escola. Sabemos que muitas vezes a prática nos ensina mais que a 
teoria. Mas a questão, além de uma formação oficial, deve ser entendida como qualificação para aqueles que desejam atuar no cuidado e na educação de crianças. Devemos olhar para a "exigência" da formação do ponto de vista de direito: pois é um direito dos profissionais, assim como é um direito das crianças (PRESTES, 2003, p. 4).

Todavia, segundo o estudo de Duarte, sem generalizar o processo de trabalho pedagógico voltado à educação da infância. De acordo com Souza (2011), algumas práticas pedagógicas de professores da Educação Infantil têm ficado à mercê do modismo intelectual e da mercantilização do processo educativo em dois eixos.

O modismo intelectual (e seus desdobramentos na Educação Infantil) objetiva andar em consonância com o cumprimento das políticas públicas de expansão das oportunidades de acesso à Educação Básica, mas sem efetivamente criar as condições necessárias ao trabalho pedagógico para uma educação de qualidade para as crianças que frequentam a Educação Infantil.

Já o segundo ponto - mercantilização do processo educativo -, refere-se especificamente à concepção educacional que sustenta os pilares de uma escolarização precoce, pois a Educação Infantil figura como fase preparatória ao Ensino Fundamental.

Desse modo, a inter-relação entre o educar-cuidar-proteger na Educação Infantil tem extrema relevância quando se discute o papel dos mediadores no processo de subjetivação-apropriação das capacidades humanas. As condições naturais são imprescindíveis; sem elas não pode haver desenvolvimento psíquico, mas, ao mesmo tempo, não são elas que determinam as qualidades de vida e de educação sob cuja influência a criança assimila a experiência social. Neste ponto, tornar-se-á fundamental compreender os desafios e as perspectivas da formação de professores para a Educação Infantil no curso de Pedagogia, elemento a ser problematizado no próximo item.

\section{Desafios e perspectivas da formação de professores para a educação infantil no curso de pedagogia}

Para listar os desafios e perspectivas da formação política e pedagógica dos professores da Educação Infantil, buscam-se as contribuições teórico-metodológicas do 
curso de Pedagogia, disciplina que alicerça os fundamentos de um campo de pesquisa ainda muito recente.

De acordo com Franco (2008), a pedagogia não tem especificidades que apontem neutralidade nas formas que emergem das relações sociais; esclarece que se encontram atrelados a ela desde os pressupostos filosóficos, sociológicos e psicológicos até a prática social. Por isso, na perspectiva filosófica do marxismo, entende-se práxis na relação dialética entre homem e a natureza. Nesta relação, o homem se transforma a partir do momento que provoca mudanças na natureza para suprir as próprias necessidades que foram criadas nesse processo de sua constituição cultural.

O curso de Pedagogia forma pedagogos. Pedagogo é o profissional que estuda o que se insere na práxis da educação na sociedade. Portanto, vale dizer que esse estudo somente poderá ser realizado como pesquisa das manifestações educativas que ocorrem nas sociedades, incluindo o ensino. Para isso são necessários os fundamentos de várias áreas do saber, inclusive daquelas que estudam o ensino. Sua inserção profissional será transformada e propositiva se baseada nesses princípios, e ocorrerá nas instituições educativas existentes e a serem criadas, que não apenas na escola. É por meio do campo profissional, da profissão que se muda o mundo. Será mediante a inserção profissional, o trabalho coletivo, que criamos as condições para sobreviver e para nos constituir como seres humanos, o que contribui para que outros também se constituam como tal, encetando assim ações transformadoras da realidade (FRANCO; LIBÂNEO; PIMENTA, 2007, p. 83).

Assim, "o pedagógico refere-se à finalidade da ação educativa, implicando objetivos sociopolíticos, a partir dos quais se estabelecem formas organizativas e metodológicas da ação educativa" (KUENZER, 2002, p. 30).

[...] o curso de Pedagogia constitui o único curso de graduação cuja especificidade é proceder à análise crítica e contextualizada da educação e do ensino como práxis social, formando o profissional pedagogo, com formação teórica, científica e técnica com vistas ao aprofundamento na teoria pedagógica, na pesquisa educacional e no exercício de atividades pedagógicas [...] (FRANCO; LIBÂNEO; PIMENTA, 2007, p. 84).

A formação do professor por meio do curso de Pedagogia, licenciatura plena, habilita também a atuação deste profissional na Educação Infantil. Em outras palavras, muitos dos desafios impostos ao trabalho pedagógico a ser desenvolvido pelo professor 
decorrem da frágil organização e gestão do espaço escolar voltado à Educação Infantil no atendimento de crianças de zero a cinco anos de idade. Tal contexto não propicia um conjunto de fatores que facilitem o desenvolvimento de uma educação de qualidade.

Sobre a valorização do profissional da educação, Bonetti (2006, p. 2) ressalta:

O reconhecimento de uma profissão implica a sua valorização quanto à remuneração, à carga horária de trabalho condizente com o título, o plano de carreira e quanto à garantia dos demais direitos trabalhistas, como férias e aposentadoria, entre outros.

Porém, a atual conjuntura nos leva a perceber a dicotomia dos discursos que envolvem a formação do professor, pois se tem disseminado uma prática que encurta o tempo de aperfeiçoamento, no qual prevalecem cursos que primam pelo desenvolvimento de habilidades manuais em detrimento da consolidação da formação em serviços que instrumentalizam o trabalhador da educação.

Talvez pela primeira vez em nosso país, começamos a pensar um perfil de educador adequado às características e necessidades de alunos em diferentes fases de seu desenvolvimento. Ou seja, começamos a pensar na criança, no adolescente, jovem, no adulto que se encontra escondido atrás da palavra "aluno" (CAMPOS, 1999 p. 127).

Portanto, com o presente estudo quer-se buscar na discussão acadêmica os elementos necessários para debater a importância da formação teórica e da qualificação político-pedagógica do professor de Educação Infantil, no intuito de trazer à tona a relevância do conhecimento teórico desse professor para a efetivação do direito da criança à educação, desde a mais tenra idade. Expor à sociedade as conquistas advindas com a expansão do acesso à Educação Infantil, que é espaço do cuidar, do educar e do proteger; que tem como objetivo evidenciar a intencionalidade educativa articulada na organização do trabalho pedagógico do professor.

\section{Considerações}

Em síntese, o papel da educação infantil, normatizado pelas legislações vigentes, traz consigo não apenas uma nova visão de criança, mas também uma nova concepção de profissional. Reitera-se que a formação docente para atuar na primeira etapa da 
Educação Básica deve incluir o conhecimento teórico e técnico, envolvendo o desenvolvimento de habilidades para realizar atividades variadas para interagir com crianças pequenas.

O professor de Educação Infantil deve desenvolver a capacidade de organização do espaço, do tempo, dos materiais, dos agrupamentos de crianças e propor atividades desafiadoras que provoquem as crianças à apropriação do conhecimento. Nisso reside a importância de significarmos as relações e condições de trabalho docente e, sobretudo, de discutirmos a preparação e a formação de professores para responder adequadamente às inusitadas e reais situações que serão criadas no cotidiano da sala de aula.

Dessa forma, a realidade social não se constrói no acaso. Por isso, nas palavras de Freire (1987, p. 21), a práxis compreende a "reflexão e ação dos homens sobre o mundo para transformá-lo, Sem ela, é impossível a superação da contradição opressoroprimidos", ou seja, a materialidade das relações sociais constitui-se como fruto da ação humana e é tarefa histórica dos homens, por meio da práxis, transformar essa mesma realidade.

Portanto, considera-se que trabalhar o pedagógico na faixa etária de zero a cinco anos exija preparação física e, sobretudo, consolidação na formação teórica.

\section{Referências}

ALMEIDA, O. A. A LDB e a formação do professor de educação infantil. 2007. Disponível em: http://www.pmcg.ms.gov.br/egov. Acesso em: 15 out. 2011.

BONETTI, N. O professor de educação infantil um profissional da educação básica e sua especificidade. In: ANPED. Caxambu, MG: 2006. CDROM 29 anos ANPED. Disponível em: www.anped.org.br/reunioes/29ra/trabalhos/.../GT07-1779--Int.pdf. Acesso em: 20 jul. 2012.

BRASIL. Constituição (1988). Constituição da República Federativa do Brasil. Brasília, DF: Senado Federal. Disponível em http://www.planalto.gov.br/ccivil_03/constituicao/constituicao.htm Acesso em: 8 mai. de 2013. 
BRASIL. Lei de Diretrizes e Bases da Educação Nacional. Lei n. 9394, de 20 de dezembro de 1996. Estabelece as diretrizes e bases da educação nacional. Brasília, DF: MEC, 1996.

BRASIL. Plano Nacional de Educação (2001-2010). Brasília: Senado Federal, UNESCO, 2001.

CAMPOS, M. M. Educar e cuidar: questões sobre o perfil do Professional de educação infantil. IN: Por uma política de formação do profissional de educação infantil. Brasília: MEC, 1999, p.32-42

DUARTE, L. F. SOUZA, M. C. B. R. Pré-escola: preparação ou transição para o ensino formal. 2011. Trabalho de Conclusão de Curso em Pedagogia - Universidade Estadual do Oeste do Paraná - Foz do Iguaçu.

FRANCO, M. A. S. Pedagogia como ciência da educação. Campinas: Papirus, 2008

FRANCO, M. A. S.; LIBÂNEO, J. C.; PIMENTA, S. G. Elementos para a formulação de diretrizes curriculares para cursos de Pedagogia. In: Cadernos de Pesquisa, 2007.

FREIRE, P. Pedagogia do Oprimido. Editora Paz e Terra, 1987.

KUENZER, A. Z. Trabalho Pedagógico: da fragmentação à unitariedade possível. In: FERREIRA, N. S. C.; AGUIAR, M. A. S. (Orgs.). Para onde vão a Orientação e a Supervisão Educacional. Campinas, São Paulo: Papirus, 2002.

MARCONI, M. de A.; LAKATOS, E. M. Técnicas de pesquisa. In: . Fundamentos de metodologia científica. 7. ed. rev. São Paulo: Atlas, 2010.

MELLO, S. A. Contribuições de Vigotski para a educação infantil. In: MENDONÇA, S. G. L.; MILLER, S. (Orgs). Vigotski e a Escola Atual: fundamentos teóricos e implicações pedagógicas. Araraquara/SP: Junqueira \& Marin, 2006.

. A Escola de Vygotsky. In: CARRARA, K. (Org.). Introdução à Psicologia da Educação: Seis Abordagens. Campinas, SP: Avercamp Editora, 2004. 
PAULA, F. A. Atendimento à criança pequena e Educação Infantil: aspectos históricos e dilemas atuais. In: SZYMANSKI, Maria Lidia Sica. (Org.). Aprendizagem e ação docente. 1. ed. Cascavel-PR: Edunioeste, v. 1, 2010. p. 45-64.

PRESTES, Z. Professor da Creche e da Pré-escola: um profissional com formação e compromisso. 2003 Disponível em:

www.sinprominas.org.br/imagensDin/arquivos/362.doc. Acesso em: 28 nov. 2011.

Recebido em: 17/03/2013

Aprovado em: 02/05/2013

Universidade do Estado de Santa Catarina - UDESC

Centro de Ciências Humanas e da Educação - FAED

Revista PerCursos

Volume 14 - Número 26 - Ano 2013

revistapercursos@gmail.com 